\title{
Научная и организационная деятельность лаборатории хроматографии Института физической химии с момента её образования
}

\author{
(C) 2020 Боровикова С.А., Коломиец Л.Н. \\ Институт физической химии и электрохимии им. А.Н. Фрумкина РАН, Москва \\ Поступила в редакцию 28.03.2020 г.
}

DOI: $10.17308 /$ sorpchrom.2020.20/2878

В 2020 г. лаборатория хроматографии и хромато-масс-спектрометрии в ИФХЭ РАН отмечает 70-летие со дня её основания. В статье рассказывается об организации лаборатории хроматографии в $\mathrm{CCCP}$, её становлении и перспективах развития. Приведены данные о наиболее важных результатах научной и организационной деятельности заведующих и сотрудников лаборатории на протяжении нескольких десятилетий.

Пионером создания хроматографии в СССЗ как научного направления стал заведующий кафедрой физической и коллоидной химии Тимирязевской сельскохозяйственной академии (ТCX) профессор Евгений Никитович Гапон (1891-1950). Значимость хроматографии в 1950 году в области научных и прикладных исследований была подтверждена созданием специальной лаборатории в Институте физической химии АН СССР.

Первым научным руководителем лаборатории хроматографии был назначен профессор Константин Васильевич Чмутов. Под его руководством были изучены закономерности статики, динамики и кинетики на цеолитах и ионитах с целью внедрения хроматографических процессов в производство. После ухода из жизни в 1979 году Константина Васильевича достойным продолжателем его научных исследователей стал д.х.н. Олег Георгиевич Ларионов (1932-2013). О.Г. Ларионовым и его сотрудниками были выполнены основополагающие работы в области жидкостно-адсорбционной хроматографии, барохроматографии и хроматографического титрования.

В 1984 году лаборатория физико-химических основ хроматографии пополнилась сотрудниками безвременно ушедшего всемирно известного физико-химика д.х.н. Андрея Владимировича Киселева Любовью Дмитриевной Беляковой, Юрием Анатольевичем Эльтековым, Натальей Петровной Платоновой.

В 2004 году лаборатория пополнилась учеными масс-спектроскопистами из лаборатории спектроскопии ИФХЭ РАН. Одним из них был д.Х.н. Алексей Константинович Буряк, который стал заведующим новой объединенной лаборатории физико-химических основ хроматографии и хроматомасс-спектроскопии. В настоящее время в лаборатории ведутся исследования по совершенствованию методов удерживания в условиях газовой хроматографии, а также выполняется теоретическое моделирование и экспериментальная проверка удерживания на углеродных хроматографических сорбентах для жидкостной и газовой хроматографии. Один из методов предсказания газохроматографических индексов удерживания на основе структуры аналита лег в основу современных методов искусственного интеллекта (в глубоких сверточных нейронных сетях).

Ключевые слова: метод хроматографии, лаборатория хроматографии, комиссия по хроматографии, физико-химические основы хроматографического анализа.

Метод хроматографии, открытый в 1903 г. русским учёным М.С. Цветом, к середине XX столетия ещё не был достаточно оценён в СССР, в то время как на Западе многие учёные начали активно использовать его в своих исследованиях. Европейские и американские химики опубликовали результаты сотен исследований, связанных с использованием хроматографии, а также несколько обобщающих моногра- 
фий об этом методе. Кроме того, некоторые из них стали лауреатами Нобелевской премии за достижения с использованием хроматографии. Создание лаборатории хроматографии в ИФХ АН СССР ознаменовало развитие хроматографии в СССР как самостоятельного научного направления.

Пионером создания хроматографического направления в СССР в пятидесятые годы был заведующий кафедрой физической и коллоидной химии Тимирязевской сельскохозяйственной академии (ТСХА) профессор Евгений Никитович Гапон (1904-1950).

Возглавлявший тогда Академию наук Сергей Иванович Вавилов (1891-1951) понимал необходимость развертывания работ по изучению и использованию хроматографии. Он поручил заняться данным вопросом академику-секретарю Отделения химических наук АН СССР Михаилу Михайловичу Дубинину (1901-1993), который был к тому же ведущим специалистом по сорбции газов, паров и растворенных веществ твердыми пористыми телами и возглавлял лабораторию сорбционных процессов в ИФХ АН СССР [1]. Весь комплекс вопросов обстоятельно прорабатывался на уровне Совета Министров СССР. В итоге, 10 июня 1949 г. появилось распоряжение СМ СССР за № 8402 рс, обязывающее различные министерства и Академию наук развернуть изучение и использование метода адсорбционной хроматографии в научных интересах и для решения ряда производственных задач в различных отраслях народного хозяйства. Академии наук предписывалось создать специальную лабораторию для фундаментальных исследований хроматографии, а для координации работ специалистов различных учреждений по данной проблематике организовать научно-общественное объединение с руководящим центром при Академии наук [2]. В итоге, работы по хроматографии стала координировать вновь созданная в ИФХ АН СССР лаборатория хроматографии.

Таким образом, начало 1950 г. ознаменовалась важными событиями для хроматографии в СССР. Впервые в нашей стране состоялось её признание в качестве современного направления, значимость хроматографии была признана не только формально на официальном уровне, но и подтверждена конкретным делом - созданием специальной лаборатории в авторитетном научном учреждении [3]. Из отчета о деятельности Института за 1950 г. известно, что были открыты две лаборатории: лаборатория хроматографии и лаборатория радиохимии, в которых проводились исследования по двум направлениям, существенно способствующих дальнейшему плодотворному развитию физической химии в Академии наук СССР [4]. Для руководства лабораторией был приглашен доктор химических наук, профессор Константин Васильевич Чмутов (1902-1979), имевший опыт решения фундаментальных проблем, требующих теоретического осмысления изучаемых сорбционных явлений с точки зрения новых экспериментальных возможностей, о чём свидетельствовали его публикации за 1925-1949 гг. Заведующий лабораторией хроматографии ИФХ К.В. Чмутов автоматически становился руководителем-координатором всех работ в стране по данной проблематике, т.е. практически председателем пока еще официально не созданной Комиссии по хроматографии [5]. Перед лабораторией хроматографии ставилась задача, целью которой было стать не только научным, но и координационным центром изучения этой проблематики. Немаловажную роль в этом деле сыграла Татьяна Борисовна Гапон [1]. В должности младшего научного сотрудника Т.Б. Гапон, продолжая дело своего безвременно ушедшего супруга, выполняла обязанности заместителя заведующего лабораторией и учёного секретаря еще пока не созданной Комиссии по хроматографии. Ею подготовлена справка «О структуре и профиле лаборатории хроматографии», отчеты о работе лаборатории 1950-1953 гг. $[6]$.

Боровикова и др. / Сорбционные и хроматографические процессы. 2020. Т. 20. № 3. С. 408-416 
С 1950 г. начинается плодотворная работа К.В. Чмутова и сотрудников в области хроматографии и ионного обмена. Будучи широко эрудированным физикохимиком, К.В. Чмутов поставил перед коллективом вновь организованной лаборатории задачу всестороннего исследования всех процессов, определяющих хроматографическое разделение. Под его руководством исследованы закономерности статики, динамики и кинетики ионообменной и молекулярной сорбции. Фундаментальные исследования равновесия, кинетики, динамики сорбции и хроматографии на цеолитах и ионитах были подчинены главной идее - интенсификации хроматографических процессов.

К.В. Чмутов уделял также большое внимание препаративному и промышленному применению хроматографии в условиях интенсивного ведения процессов при больших нагрузках, температурах, скоростях. В работах К.В. Чмутова и его сотрудников установлено, что в ряде случаев наибольшая интенсификация препаративных хроматографических процессов получения чистых веществ достигается при переходе от проявительного режима к вытеснительному. При этом достигается исключительно высокая чистота продуктов [3].

В 1953 г. К.В. Чмутова избрали членом-корреспондентом АН СССР, а со дня основания Комиссии по хроматографии (Постановление № 32 от 23 января 1953 г.) и затем Научного совета по хроматографии АН СССР Константин Васильевич Чмутов бессменно руководил этой организацией, объединившей всех хроматографистов страны.

Для решения задач выделения и очистки изотопов в лаборатории была организована группа, которую возглавил Петр Павлович Назаров (1915-1990). В группе проводились секретные разработки в области атомной энергетики. В 1974 г. группа П.П. Назарова была преобразована в лабораторию хроматографии радиоактивных элементов, которая вошла в созданный в этом же году Отдел хроматографии. 29 мая 1979 г. Константина Васильевича не стало, но созданная им лаборатория и прекрасная хроматографическая школа существуют и сегодня.

Достойным продолжателем традиций, заложенных К.В. Чмутовым, стал его любимый ученик д.Х.н. Олег Георгиевич Ларионов (1932-2013). Он возглавил лабораторию, а также стал Председателем Научного совета по хроматографии АН СССР. О. Г. Ларионов выполнил свою дипломную работу (1955 г.), а затем защитил кандидатскую диссертацию (1962 г.) в ИФХ АН СССР. В 1976 г. О.Г. Ларионов там же защитил докторскую диссертацию. Вся научная и организаторская деятельность О.Г. Ларионова прошла в ИФХ АН СССР, где он прошел путь от лаборанта до заведующего Отделом хроматографии.

О.Г. Ларионовым и его сотрудниками выполнены фундаментальные исследования по термодинамике адсорбции из растворов и применению хроматографии в физико-химических исследованиях. Эти исследования позволили создать физикохимические основы хроматографического анализа в области жидкостноадсорбционной хроматографии, барохроматографии и хроматографического титрования. Исследования в области хроматографии привели к созданию актуального научного направления - применение хроматографии в физико-химических исследованиях.

Работы О.Г. Ларионова по исследованию активных центров на поверхности адсорбентов разного типа методом жидкостной хроматографии получили всемирную известность. Большое научное и практическое значение имели работы, посвященные исследованию биологически-активных соединений.

В 1989 г. реорганизация Института, включающая в себя разделение отделов, привела к созданию трех лабораторий: лаборатории хроматографии, заведующим 
которой остался д.х.н., профессор О.Г. Ларионов, лаборатории хроматографии радиоактивных элементов - заведующий д.х.н. П.П. Назаров и лаборатории препаративной хроматографии во главе с д.х.н. Анатолием Ивановичем Калиничевым.

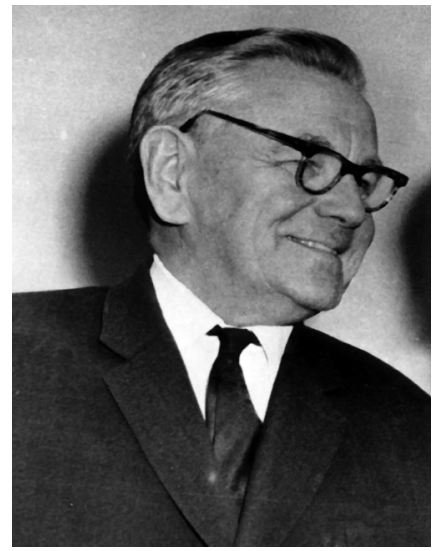

Член-корр. АН СССР К.В. Чмутов

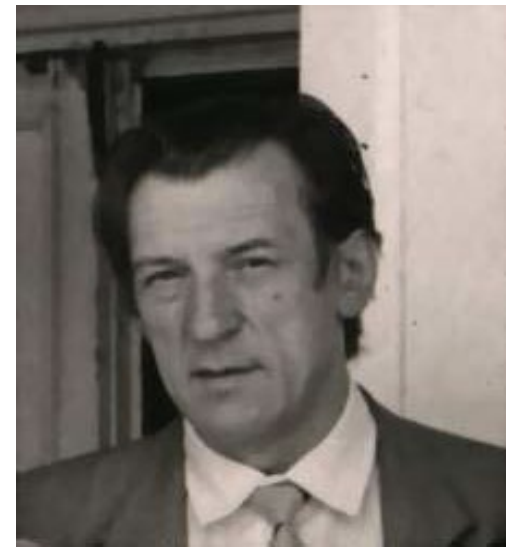

д.х.н., профессор

О.Г. Ларионов

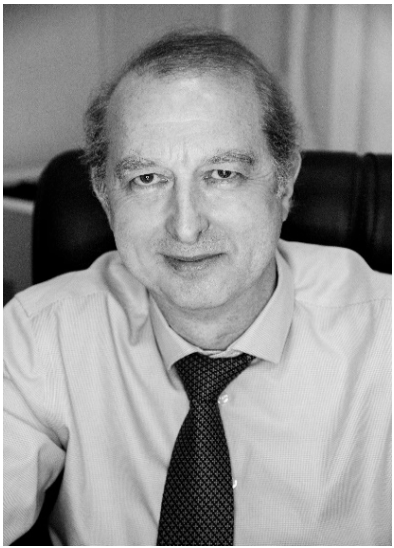

Член-корр. РАН

А.К. Буряк

В это же время к лаборатории О.Г. Ларионова присоединились сотрудники безвременно ушедшего всемирно известного физико-химика проф., д.х.н. Андрея Владимировича Киселёва (1908-1984). Среди них Любовь Дмитриевна Белякова, Юрий Анатольевич Эльтеков, Наталья Петровна Платонова, которые и по сей день продолжают принимать активное участие в жизни лаборатории. С их приходом существенно расширилась научная деятельность лаборатории, помимо работ в области жидкостной хроматографии, активно стали вестись исследования по газоадсорбционной хроматографии, включая работы на полимерных сорбентах, графитированной термической саже (ГТС), силохромах и $\mathrm{BaSO}_{4}$ [8]. Объединение с группой сотрудников А.В. Киселёва повлекло за собой изменение названия лаборатории, которая стала называться лабораторией физико-химических основ хроматографии.

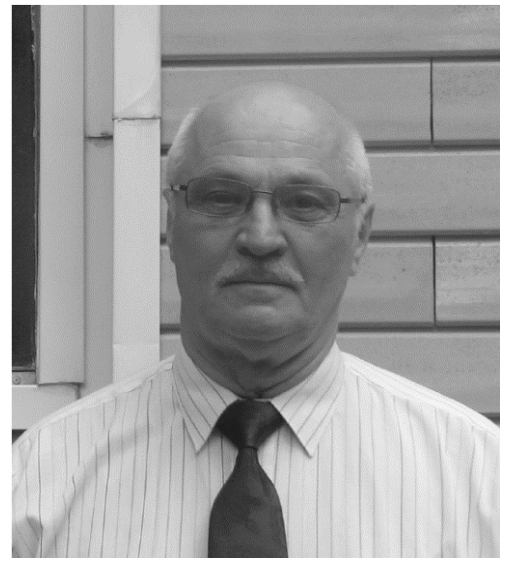

д.х.н. А.И. Калиничев

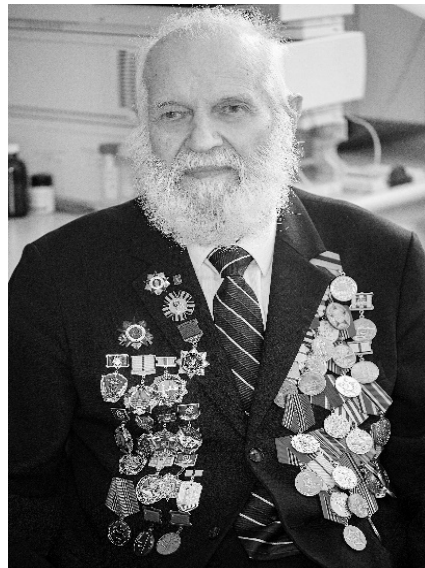

к.Х.Н., ст.н.с. Ю.А. Эльтеков

Научную работу Олег Георгиевич совмещал с большой организационной деятельностью. С 1980 по 1991 год О.Г. Ларионов являлся председателем Научного совета АН СССР по хроматографии, с 1992 года - заместителем председателя этого же совета, с 1999 года - заместителем председателя Объединенного научного совета РАН по адсорбции и хроматографии, более десяти лет был членом бюро Научного совета РАН по аналитической химии. 


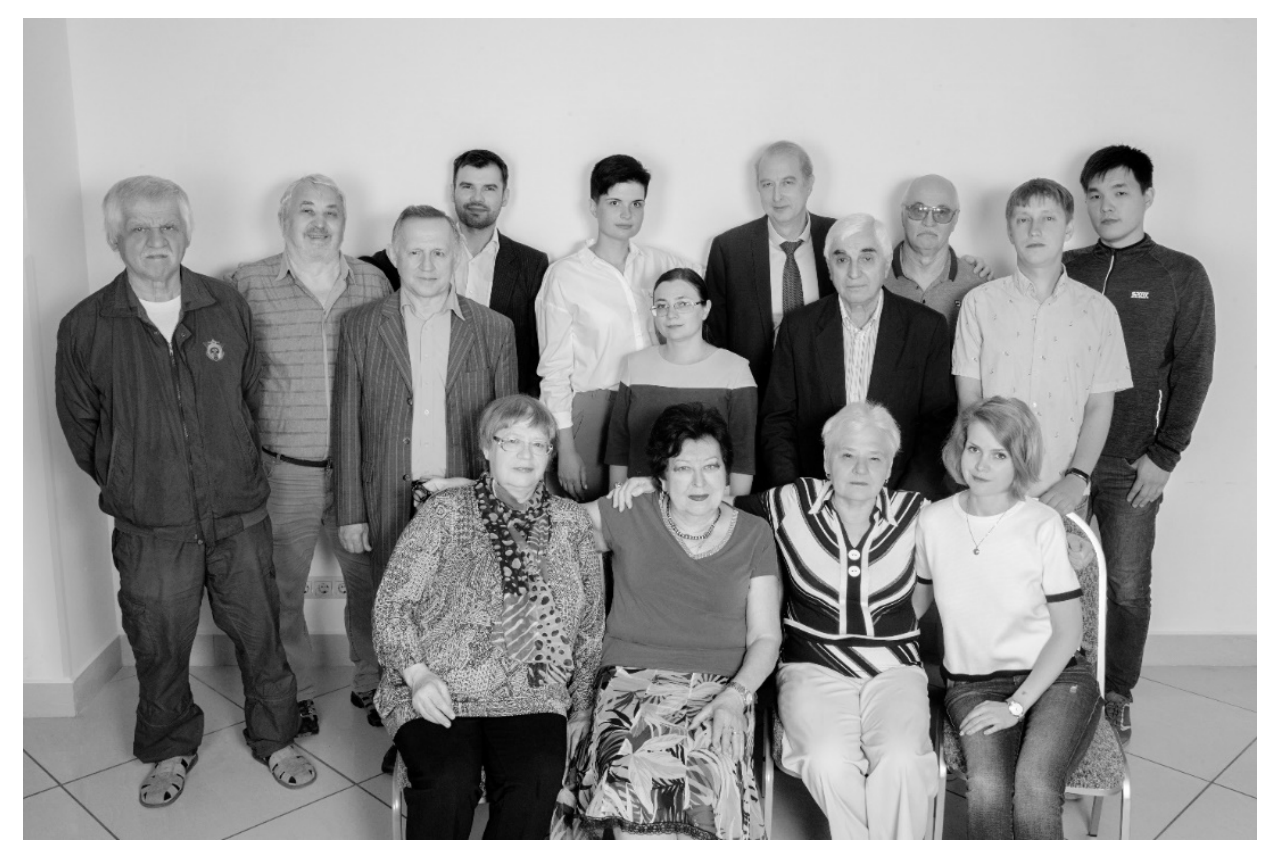

Слева направо: сидят - н.с. Е.В. Колотинская, с.н.с., к.х.н. Л.Н. Коломиец, ст.н.с., к.х.н. Н.П. Платонова, с.н.с., к.х.н. Е.С. Кузнецова;

стоят - с.н.с., к.Х.н. С.А. Бусев, н.с. В.Я. Филимонов, с.н.с., к.х.н. В.Б. Хабаров, н.с., к.х.н. А.Ю. Эльтеков, м.н.с., к.Х.н. А.Ю. Шолохова, м.н.с.,

к.х.н. И.В. Миненкова, зав. лаб., Д.Х.н. А.К. Буряк, с.н.с., к.х.н. Э.С. Якубов, гл.н.с., Д.Х.н. А.И. Калиничев, с.н.с., к.х.н. И.С. Пыцкий, м.н.с. А.Ю. Доржинов

О.Г. Ларионов являлся председателем серии Международных симпозиумов ИЮПАК по химии поверхности и хроматографии (1988, 1992, 1998 годы), постоянным членом научного комитета Дунайских симпозиумов по хроматографии и председателем V Дунайского симпозиума (Ялта, 1985), председателем, сопредседателем и членом оргкомитетов всесоюзных и всероссийских симпозиумов по хроматографии и ионному обмену, членом научного комитета серии международных симпозиумов «Хроматография и спектроскопия объектов окружающей среды и токсикология» (1993, 1996 годы), председателем Всероссийского симпозиума «Современные проблемы хроматографии», который состоялся в 2003 году. В 2006 году Олег Георгиевич был сопредседателем X Международной конференции «Теоретические проблемы химии поверхности, адсорбции и хроматографии. Олег Георгиевич поддерживал тесные научные контакты с российскими и зарубежными учеными. Он являлся председателем рабочей группы по химии научно-технического сотрудничества СССР - Финляндия (1982-1991 годы), был членом-корреспондентом Финляндского химического общества.

В 1990 по инициативе Олега Георгиевича Ларионова и при непосредственном участии его, а также Людмилы Николаевны Коломиец, ученого секретаря Научного совета, была открыта специальность 02.00.20 «Хроматография», которая просуществовала около 20 лет. К сожалению, в 2009 году решением ВАК специальность была приостановлена.

В 2004 году лаборатория физико-химических основ хроматографии пополнилась учёными масс-спектрометристами из лаборатории спектроскопии ИФХЭ РАН. Одним из них был д.х.н. Алексей Константинович Буряк, который стал заведующим новой объединённой лаборатории физико-химических основ хроматографии и хромато-масс-спектрометрии. Прекрасные традиции лаборатории, созданные К.В. Чмутовым и О.Г. Ларионовым, А.К. Буряк поддерживает и по сей день. 
В настоящее время в лаборатории физико-химических основ хроматографии и хромато-масс-спектрометрии ведутся исследования по разработке методов нецелевого анализа. Для идентификации используют сочетание методов вычислительной химии, хемоинформатики и экспериментальных хромато-масс-спектрометрических методов. В последнее время были разработаны наиболее точные в мире методы предсказания газо-хроматографических индексов удерживания на основании структуры аналита. Один из методов основан на современных методах искусственного интеллекта (глубоких сверточных нейронных сетях) и позволяет предсказать индекс удерживания для газо-жидкостной хроматографии (полярные и неполярные жидкие неподвижные фазы). Другой подход основан на непосредственном моделировании адсорбции молекул на поверхности углеродного сорбента (газо-адсорбционная хроматография) и является прямым продолжением работ А.В. Киселева. В последние годы разработан вариант молекулярно-статистического метода с учетом внутреннего вращения, позволяющий предсказывать удерживание на графитированной термической саже для конформационно нежестких молекул. Ведутся работы по дальнейшему совершенствованию методов предсказания удерживания в условиях газовой хроматографии. Разработан новый подход для применения индексов удерживания (предсказанных или содержащихся в базе данных) для идентификации с помощью масс-спектральных баз данных. Кроме того, ведутся работы по предсказанию фрагментации в различных методах масс-спектрометрии и анализа масс-спектров с помощью методов машинного обучения (Д.Д. Матюшин) [9].

Выполняется теоретическое моделирование и экспериментальное изучение удерживания на углеродных хроматографических сорбентах как для газовой, так и для жидкостной хроматографии. Открыты своеобразные закономерности удерживания изомерных пептидов на углеродных сорбентах и показана возможность применения этих закономерностей для анализа биологически важных объектов [10].

Основное внимание А.К. Буряк и его сотрудники уделяют разработке физикохимических основ использования различных вариантов хромато-массспектрометрии при решении актуальных задач ракетно-космической отрасли. Разработаны методы исследования состава ракетных топлив, поверхностей конструкционных материалов и объектов окружающей среды, подвергающихся воздействию негативных последствий ракетно-космической деятельности. Выполнены работы, имеющие большое значение для минимизации экологического ущерба от деятельности ракетно-космической отрасли. Многие работы посвящены анализу токсичных соединений, образующихся в ходе использования ракетных топлив [11]. Массспектрометрическими исследованиями физико-химии поверхности конструкционных материалов, применяемых в ракетной технике, активно занимается с.н.с., к.Х.н. Иван Сергеевич Пыцкий [12].

Под руководством ведущего научного сотрудника лаборатории физикохимических основ хроматографии и хромато-масс-спектрометрии, кандидата химических наук Сайфутдинова Булата Ренатовича выполняются работы, касающиеся новых функциональных композиционных материалов на основе микропористых металлоорганических каркасных структур и мезопористых неорганических носителей для селективной адсорбции, разделения и каталитических превращений органических соединений [13].

Продолжаются работы по газо-адсорбционной хроматографии на сорбентах, модифицированных наночастицами различных металлов, направленные на изучение химии поверхности новых функциональных материалов [14].

Старший научный сотрудник лаборатории к.Х.н. Хабаров Виктор Борисович развивает практически важное направление по исследованию молекулярно- 
массового распределения олигомерных органических, неорганических и природных соединений. Для развития этих работ им разработан новый вариант рефрактометрического детектора, обладающего повышенной чувствительностью [15].

Старшей научный сотрудник лаборатории, к.х.н., ветеран Великой Отечественной войны Ю.А. Эльтеков продолжает работать по обобщению многолетних исследований адсорбции из растворов полимерных молекул [16].

После реорганизации научных советов в 2009 г. Научный совет по хроматографии вошел в состав Научного совета РАН по физической химии в виде секции «Физико-химия поверхности, кинетика и динамика обменных процессов». В рамках секции ежегодно проводятся конференции и симпозиумы с международным участием по хроматографии и хромато-масс-спектрометрии серии «Кинетика и динамика обменных процессов», в работе которых принимают участие ведущие и молодые учёные, представители зарубежных и отечественных фирм по аналитическому приборостроению, а также научных и научно-технических журналов. Председатель Симпозиума - Алексей Константинович Буряк, бессменный учёный секретарь Людмила Николаевна Коломиец.

Лаборатория сотрудничает с ведущими хроматографическими центрами нашей страны, представленные химическими факультетами: МГУ, Воронежа, Самары, Санкт-Петербурга, Новосибирска и др.

\section{Список литературы}

1. Рачинский В.В. 90-летие хроматографии и развитие ее теории: вопросы истории и состояния проблемы. Отчет о НИР «Разработка теории явлений динамики сорбции и хроматографии». М.: ВНТИЦ. - 1993. № 01.90.003423. 12c.

2. Архив РАН, ф.2. оп. 6-а. д.102.

3. Сенченкова Е.М. // Сорбиионные и хроматографические проиессы. 2003. Т. 3. № 2. C. $122-139$.

4. Константин Васильевич Чмутов. Материалы к библиографии ученых СССР. М. Наука. 1967. 51 с.

5. Константин Васильевич Чмутов. Статьи, воспоминания, выступления. М. 1996. 84 с.

6. Рефераты докладов на Совещании по хроматографии 21-24 ноября 1950 г. М. Издво АН СССР. 1950. $88 \mathrm{c}$.

7. Busev S.A., Zverev S.I., Larionov O.G., Jakubov E.S. // Journal of Chromatography A. 1982. Vol. 241. No 2. pp. 287-294.

8. Ненайденко С.А., Белякова Л.Д., Ларионов О.Г., Алишоев В.Р. и др. // Журнал физической химии. 1993. Т. 67. № 10. С. $2005-$ 2010.
9. Matyushin D.D., Sholokhova A.Yu., Buryak A.K. // Journal of Chromatography A. 2019. Vol. 1607, 460395. doi:10.1016/j.chroma.2019.460395

10.Milyushkin A.L., Matyushin D.D., Buryak A.K. // Journal of Analytical Chemistry. 2018. Vol. 73. No 10. pp. 999-1002.

11.Буряк А.К., Сердюк Т.М. // Усnехи химии. 2013. Т. 82. № 4. С. 369-392.

12.Iartsev S.D., Matyushin D.D., Pytskii I.S., Kuznetsova E.S. et al. // Surface Innovations. 2018. Vol. 6. No 4-5. pp. 244-249. https://doi.org/10.1680/jsuin.18.00015

13.Сайфутдинов Б.Р., Буряк А.К. // Коллоидный журнал. 2019. Т. 81. № 5. С. 605-612.

14. Шафигулина А.Д., Ревина А.А., Платонова Н.П., Боровикова С.А. и др. // Коллоидный журнал. 2019. Т. 81. № 3. C. 360-366.

15.Хабаров В.Б., Львов А.И., Буряк А.К., Хабаров М.В. Патент на изобретение RUS 258937427.03 .2015

16.Эльтеков Ю.А. Сорбция в полимерных системах. Адсорбция полимеров пористыми и непористыми телами. Гл 13, 15, 18 в кн. Гребенщиков С.Ф. С-Пб. ГС-ПбУТД. 2014. $286 \mathrm{c}$. 


\title{
The history of research and organisational activity at the laboratory of chromatography of the institute of physical chemistry
}

\author{
(C) 2020 Borovikova S.A., Kolomiets L.N. \\ A.N. Frumkin Institute of Physical Chemistry and Electrochemistry of the Russian Academy of Sciences, \\ Moscow
}

In 2020, the Laboratory of Physicochemical Principles of Chromatography and Gas Chromatography-Mass Spectrometry of the Institute of Physical chemistry and Electrochemistry of RAS is celebrating its 70th anniversary. The article describes the history of the laboratory, from its opening and development in the USSR to the current development prospects. It also describes the most important scientific and organisational achievements of the laboratory's heads and staff over several decades.

It was Professor Evgeny N. Gapon (1891-1950), Head of the Department of Physical and Colloid Chemistry of Moscow Timiryazev Agricultural Academy (MAA), who pioneered the field of chromatography in the USSR. In 1950, the value of chromatography for scientific projects and applied research was demonstrated by the opening of a special laboratory at the Institute of Physical Chemistry of the USSR Academy of Sciences.

The first head of the Laboratory of Chromatography was Professor Konstantin V. Chmutov. He supervised the studies of the principles of statics, dynamics, and kinetics on zeolites and ion exchangers performed in order to implement chromatographic processes in industrial production.

After his death in 1979, the research was continued by Oleg G. Larionov (1932-2013), DSc in Chemistry. Oleg Larionov and the laboratory's researchers performed the key studies in the field of liquidsolid chromatography, barochromatography, and chromatographic titration. In 1984, the Laboratory of Physicochemical Principles of Chromatography welcomed new members - Lyubov D. Belyakova, Yury A. Eltenkov, and Natalia P. Platonova, former colleagues of the late Andrey V. Kiselev, DSc in Chemistry and a world famous physical chemist.

In 2004, the laboratory invited more new members: researchers from the Laboratory of Spectroscopy of IPCE RAS specialising in mass spectrometry, including Alexey K. Buryak, DSc in Chemistry, who was appointed the Head of a new Laboratory of Physicochemical Principles of Chromatography and Gas Chromatography-Mass Spectrometry. Currently the laboratory staff perform research aimed at improving the retention methods in gas chromatography and theoretical modelling and experimental testing of retention on carbon and chromatography sorbents for liquid and gas chromatography. One of the methods for predicting the gas chromatographic retention indices based on the analyte's structure is used in modern artificial intelligence techniques (deep convolutional neural networks).

Keywords: chromatography, laboratory of chromatography, chromatography commission, physicochemical principles of chromatographic analysis.

\section{References}

1. Rachinsky V.V., 90th anniversary and the development of her theory: questions of history and the state of the problem, Research Report, M., VNTITS, 1993, No 01.90.003423,12 p.

2. Archive of RAS. f.2. op. 6-a. d.102.

3. Senchencova E.M., Sorptsionnye I khromatograficheskie protsessy, 2003, Vol. 3, No 2, pp. 122-139.

4. Konstantin Vasilyevich Chmutov. Materials for the bibliography of scientists of the USSR, M., Nauka, 1967, 51 p.

5. Konstantin Vasilyevich Chmutov. Articles, memoirs, speeches, M., 1996, 84 p.
6. Abstracts of reports at the Meeting on chromatography November 21-24, 1950, M., Izd-vo AS USSR, 1950, 88 p.

7. Busev S.A., Zverev S.I., Larionov O.G., Jakubov E.S., Journal of Chromatography A, 1982, Vol. 241, No 2, pp. 287-294.

8. Nenaidenko S.A., Belyakova L.D., Larionov O.G., Alishoev V.R. et al., J. of Physical Chemistry, 1993, Vol. 67, No 10, pp. 20052010.

9. Matyushin D.D., Sholokhova A.Yu., Buryak A.K., Journal of Chromatography A, 2019, Vol. 1607, 460395.

doi:10.1016/j.chroma.2019.460395 
10.Milyushkin A.L., Matyushin D.D., Buryak 14.Shafigulina A.D., Revina A.A., Platonova A.K., Journal of Analytical Chemistry, 2018, N.P., Borovikova S.A., et al., Colloid Journal, Vol. 73, No 10, pp. 999-1002. 2019, Vol. 81, No 3, pp. 292-297. DOI:

11.Buryak A.K., Serduyk T.M., Success of 10.1134/S1061933X19030128 chemistry, 2013, Vol. 82, No 4, pp. 369-392.

15.Khabarov V.B., Lvov A.I., Buryak A.K., 12.Iartsev S.D., Matyushin D.D., Pytskii I.S., Khabarov M.V., Patent for invention RUS Kuznetsova E.S. et al., Surface Innovations, 258937427.03 .2015

2018, Vol. 6, No 4-5, pp. 244-249. 16.Eltekov Yu.A. Chapters 13, 15, 18 in the https://doi.org/10.1680/jsuin.18.00015

13.Saifutdinov B.R., Buryak A.K., Colloid Journal, 2019, Vol. 81, No 5, pp. 555-562. DOI: 10.1134/S 1061933X19050107

Коломиец Людмила Николаевна - старший научный сотрудник, кандидат химических наук, Институт физической химии и электрохимии им. А.Н.Фрумкина РАН, Москва

Боровикова Светлана Александровна научный сотрудник, кандидат химических наук, Институт физической химии и электрохимии им. book. Grebenshchikov S.F.S-Pb, GS-PbUTD, 2014, 286 p.

А.Н.Фрумкина РАН, Москва

Kolomiets Liudmila N. - researcher, Ph.D. Frumkin Institute of Phisical and Electrochemistry, Moscow, e-mail: kolom moscow@mail.ru

Borovikova Svetlana A. - researcher, Ph.D. Frumkin Institute of Phisical and Electrochemistry, Moscow 